\title{
Exploring the potential of the RPA system SUMO for multipurpose boundary-layer missions during the BLLAST campaign
}

\author{
Joachim Reuder $^{1}$, Line Båserud ${ }^{1}$, Marius O. Jonassen ${ }^{1,2}$, Stephan T. Kral ${ }^{1}$, and Martin Müller ${ }^{3}$ \\ ${ }^{1}$ Geophysical Institute, University of Bergen, and Bjerknes Centre for Climate Research, Allegaten 70, \\ 5007 Bergen, Norway \\ ${ }^{2}$ UNIS - The University Centre in Svalbard, 9171 Longyearbyen, Norway \\ ${ }^{3}$ Lindenberg und Müller GmbH \& Co. KG, Hohenhameln, Germany \\ Correspondence to: Joachim Reuder (joachim.reuder@gfi.uib.no)
}

Received: 27 December 2015 - Published in Atmos. Meas. Tech. Discuss.: 19 January 2016

Revised: 18 May 2016 - Accepted: 20 May 2016 - Published: 24 June 2016

\begin{abstract}
In June and July 2011 the RPAS (Remotely Piloted Aircraft System) SUMO (Small Unmanned Meteorological Observer) performed a total number of 299 scientific flights during the BLLAST (Boundary Layer Late Afternoon and Sunset Turbulence) campaign in southern France. Three different types of missions were performed: vertical profiling of the mean meteorological parameters (temperature, humidity and wind), horizontal surveys of the surface temperature and horizontal transects for the estimation of turbulence. The manuscript provides an introduction to the corresponding SUMO operations, including regulatory issues and the coordination of manned and unmanned airborne operations for boundary-layer research that have been pioneered during the BLLAST campaign.

The main purpose of the SUMO flight strategy was atmospheric profiling at high temporal resolution. A total of 168 profile flights were performed during the campaign with typically more than 10 flights per Intensive Observational Period (IOP) day. The collected data allow for a detailed study of boundary-layer structure and dynamics and will be used for further analysis, e.g. the determination of profiles of sensible and latent heat fluxes. First, tests of a corresponding method have shown very promising results and have provided surface-flux values in close agreement with those from ground-based eddy-covariance measurements. In addition, 74 horizontal surveys of the IR emission of the surface were performed at altitudes of around $65 \mathrm{~m}$. Each of those surveys covers a typical area of around $1 \mathrm{~km}^{2}$ and allows for an estimation of the surface-temperature variability, important information for the assessment of the heterogeneity
\end{abstract}

of the surface forcing as a function of soil and vegetation properties. The comparison with other surface-temperature measurements shows that the raw data of the airborne and ground observations can differ considerably, but that even a very simple multiple regression method can reduce those differences to a large degree. Finally, 49 flight missions for the measurement of velocity variance have been realized during the BLLAST campaign. For that, SUMO has been equipped with a 5-hole probe (5HP) sensor for the determination of the flow vector at $100 \mathrm{~Hz}$. In particular, for this application there is still need for further improvement, both with respect to the aircraft and sensor hard- and software, and the algorithms and methods for data analysis and interpretation. Nevertheless, the SUMO operations during the BLLAST campaign have shown the vast potential of small and lightweight RPA systems with low infrastructural demand for atmospheric boundary-layer research.

\section{Introduction}

The atmospheric boundary layer (ABL) and in particular the surface layer (SL) directly adjacent to the ground are characterized by large spatial and temporal variability, especially over non-homogeneous land-use and terrain. The required resolution in space and time for an appropriate characterization and investigation of a wide range of related phenomena by classical boundary-layer instrumentation, e.g. meteorological masts and towers or ground-based remote sensing 
profilers such as sodars, radars or lidars, is therefore logistically demanding and not easy to achieve.

Starting with the pioneering work of Konrad et al. (1970) in the 1970s, boundary-layer researchers began to use remotely controlled aircraft for atmospheric measurements (e.g. Egger et al., 2002, 2005; Spengler et al., 2009; Reuder et al., 2011). With the availability of reasonably priced and sized autopilot systems, a considerable number of fixed and rotary-wing airframes of different size, endurance and complexity have found their way into atmospheric research during the last decade (e.g. Holland et al., 2001; Shuqing et al., 2004; Spiess et al., 2007; Elston et al., 2011; Wildmann et al., 2014). A comprehensive summary and overview has recently been compiled and published by Elston et al. (2015).

The ABL, with a typical vertical extent on the order of hundreds of metres to a few kilometres, is a natural target for measurements with relatively small and lightweight RPA (Remotely Piloted Aircraft) systems of limited payload capacity and endurance. The rapid development in the field of microelectronics and microelectromechanical systems (MEMS) during the last years has provided smaller, faster and more energy-efficient sensors, both for atmospheric measurements and the attitude determination and control of the airframes. As a consequence of this miniaturization, even very small and lightweight RPA systems with a take-off weight below $1 \mathrm{~kg}$ are now capable of carrying various sensors for multiple BL measurements.

One of those systems is the Small Unmanned Meteorological Observer (SUMO), a collaborative development between the Geophysical Institute at the University of Bergen (GFI/UiB), Norway and Lindenberg und Müller GmbH \& Co. KG, a small enterprise specializing in unmanned system development for atmospheric research in Hildesheim, Germany. A detailed description of the basic SUMO system and its ongoing development can be found in Reuder et al. (2009, 2012). The mechanical properties of the aircraft are open source, and the blueprints and building instructions are freely available. Besides GFI/UiB, which currently owns and operates four SUMO systems, several other institutes worldwide have started to use it recently. To the knowledge of the authors, these are the Finnish Meteorological Institute (FMI), the University Centre in Svalbard (UNIS), the Universities of Oklahoma (OU) and Colorado Boulder (CU) in the United States and ETH in Zürich, Switzerland.

In the past, the SUMO system has mostly been used for $\mathrm{ABL}$ profiling missions to investigate various localscale meteorological phenomena, often in combination with mesoscale numerical simulations. Some examples are studies on terrain-induced flow modification at the Hofsjökull glacier in central Iceland (Mayer et al., 2010) with the potential benefit of assimilating SUMO data into the numerical weather forecast model WRF to improve the short-term prediction capabilities (Jonassen et al., 2012), a detailed study of the polar BL in Advent Valley, Svalbard (Mayer et al., 2012) or the investigation of the effect of Nunataks on local meteorology in Antarctica (Stenmark et al., 2014). A large portion of the SUMO operations have taken place in polar regions (e.g. Cassano, 2014; Mayer et al., 2012; Jonassen et al., 2015), documenting the robustness, flexibility and low infrastructural demands of the SUMO system. In this context, the hand-starting capability of the SUMO system has proven to be a huge benefit compared to the larger airframes that require starting aid in the form of a catapult or at least a bungee cord, the latter being negatively affected both by very low and very high temperatures. A modified SUMO aeroplane has been equipped with a specifically designed 7-hole flow probe that has been developed by ETH in Zürich, Switzerland (Kocer et al., 2011; Subramanian et al., 2015) for the purpose of turbulence measurements in the wake of wind turbines. The integration of a 5-hole probe (5HP) on the SUMO systems of GFI (Reuder et al., 2012; Båserud et al., 2014) is also partly motivated by that purpose, but will of course also be beneficial for ABL research in general.

The main objective of the study is the presentation of the capability of the SUMO system to perform a wide range of specific and targeted flight missions and to give an indication of the quality and application of the data sets obtained. This analysis will help describe the added value of such missions in the framework of a large atmospheric boundary-layer campaign.

The manuscript is organized as follows. Section 2 gives a short overview of the SUMO airframe and sensor payload used during the BLLAST (Boundary Layer Late Afternoon and Sunset Turbulence) campaign. A general description of the campaign with focus on the RPAS operations, including regulatory issues and the coordination between manned and unmanned aircraft operations, is presented in Sect. 3 together with the detailed description of the different types of flight missions of the SUMO system. Exemplary results are introduced and discussed in Sect. 4 before the manuscript ends with a short conclusion and outlook.

\section{The SUMO system}

The Small Unmanned Meteorological Observer (SUMO) is a micro-RPAS with a length and wingspan of $80 \mathrm{~cm}$ and a takeoff weight of around $650 \mathrm{~g}$ (Reuder et al., 2009) and has been continuously improved and developed during the last years (Reuder et al., 2012). The main differences in airframe, autopilot and meteorological sensor package (Table 1) between the version described in Reuder et al. (2012) and the system finally deployed during the BLLAST campaign are described in the following.

\subsection{Airframe}

The SUMO airframe is based on the commercially available model aircraft kit FunJet by Multiplex, which has been reinforced by glass fibre coating at the bottom of the fuselage, the front part of the wing and the base for the motor at the 
Table 1. Specifications of the meteorological sensors.

\begin{tabular}{lllll}
\hline Parameter & Sensor & Range & Accuracy & Acquisition frequency \\
\hline Temperature & Sensirion SHT75 & -40 to $124^{\circ} \mathrm{C}$ & $\pm 0.3^{\circ} \mathrm{C}$ & $2 \mathrm{~Hz}$ \\
Humidity & Sensirion SHT75 & 0 to $100 \%$ & $\pm 2 \%$ & $2 \mathrm{~Hz}$ \\
Temperature & PT1000 Heraeus M222 & -32 to $96^{\circ} \mathrm{C}$ & $\pm 0.2^{\circ} \mathrm{C}$ & $8.5 \mathrm{~Hz}$ \\
Pressure & MS 5611 & 300 to $1200 \mathrm{hPa}$ & & $4 \mathrm{~Hz}$ \\
Surface temperature & Melexis MLX90614 & & & $8.5 \mathrm{~Hz}$ \\
3-D flow vector & 5-hole probe (5HP), Aeroprobe & 11 to $35 \mathrm{~m} \mathrm{~s}^{-1}$ & $\pm 0.1 \mathrm{~m} \mathrm{~s}^{-1}$ & $100 \mathrm{~Hz}$ \\
\hline
\end{tabular}

rear part of the fuselage. These modifications enhance the aircraft stiffness and resistance against damage from landings on rough surfaces, thus improving the airframe's durability and also flight performance. The top of the entire fuselage can be removed to allow easy access to the sensors and electronics inside.

\subsection{Autopilot and control units}

The autopilot system in use is Paparazzi, an open source hardware and software autopilot system, developed and maintained under the lead of the École Nationale de l'Aviation Civile, Toulouse, France (Brisset et al., 2006; ENAC, 2008). A new compact and lightweight IMU (Inertia Measurement Unit) system has been integrated for the measurement of the aircraft's attitude as an replacement for the previously used IR sensor array. This extends the operation of SUMO to a much wider range of atmospheric conditions, such as flight missions under low or even within clouds, which could not be performed before, since the IR-based attitude control required a certain minimum temperature difference between the sky and the ground to work properly. Besides the extended applicability, this also improved the reliability and the overall performance of the autopilot and provides us with more accurate measurements of the pitch and roll angles, which are required for the calculation of turbulent parameters from the turbulence measurement system.

\subsection{Basic meteorological parameters}

The basic meteorological parameters pressure, temperature and humidity are measured by an integrated set of sensors as summarized in Table 1. The temperature and humidity sensors are mounted on top of the wings inside radiation protection tubes and are well ventilated during flight missions. The pressure sensor is mounted inside the fuselage for better protection and is combined with an additional temperature sensor, which is used for monitoring the thermal state of the battery and electronic components; information of particular importance for operations in hot or cold environments. A second temperature sensor (PT1000) with a response time of about $1 \mathrm{~s}$ has been implemented for an improved temperature-height assignment during profile measurements.

\subsection{Turbulence}

The integration of a 5HP and the corresponding pressure transducers and data logger (Aeroprobe, 2012; Reuder et al., 2012), enables the measurement of the 3-D flow vector in the Lagrangian system of the RPAS at a temporal resolution of $100 \mathrm{~Hz}$, a sufficient resolution for the calculation of turbulence parameters, such as the turbulence kinetic energy (TKE) or the turbulent momentum flux $(\tau)$, also referred to as Reynolds stress. The probe is mounted in the nose of the airframe and is connected to the differential pressure sensors in the logging unit by six silicon tubes of about $10 \mathrm{~cm}$ length. The tip of the sensor is located approximately $10 \mathrm{~cm}$ in front of the fuselage. The key specifications of the turbulence sensor are also listed in Table 1. During the BLLAST campaign, the Aeroprobe system had not yet been fully integrated into the SUMO data acquisition system so that two different data loggers were in use, inducing additional challenges for the post-processing of the turbulence data due to unsynchronized data loggers. This is described in more detail in Båserud et al. (2016). Another problem related to determining turbulence parameters is related to the lack of a precise method for measuring the aircraft's yaw angle, which has to be known for the transformation of the measured flow field into an earth-fixed coordinate system. In multicopters, typically magnetometers are applied for this purpose; however they do not provide a very precise angle estimation. In addition, the small dimension of the SUMO system does not allow for a sufficient separation distance between the magnetometer and the cables connecting the battery and the motor. Therefore the magnetic field, induced by the electric current required for powering the motor during flight, will be a further source of uncertainty.

\subsection{Surface temperature}

A downward-looking infrared (IR) sensor, MLX90614, produced by Melexis and mounted on one of the wings, can be used to give an estimate of the surface temperature. The sensor consists of a thermopile detector chip, sensitive for infrared radiation, and a signal processing unit integrated in a TO-39 housing, i.e. a small metal cylinder with $8.2 \mathrm{~mm}$ diameter and $4.1 \mathrm{~mm}$ length. The angle of view of this sensor is $90^{\circ}$, so that the measured radiation originates from a cir- 
cular footprint area with a diameter that is equal to the flight level above ground, assuming horizontal flight with zero pitch and roll. Therefore, the calculated surface temperatures have to be regarded as a mean temperature estimate of the footprint area. The information on the longwave radiation, emitted by the surface, can be converted to a corresponding surface temperature by applying the Stefan-Boltzmann law and corresponding corrections for atmospheric absorption and emission in the atmospheric layer between the sensor and the surface.

\section{The BLLAST campaign}

The BLLAST field campaign (Lothon et al., 2014) was conducted from 14 June to 8 July 2011 at and around Lannemezan in southern France. A wide range of ground-based and airborne instrumented platforms were deployed and used, including remote-sensing profilers, radiosondes, tethered balloons, surface-flux stations and meteorological towers, as well as manned full-size aircraft and RPAS. Using this instrumentation, the boundary-layer structure and evolution from the earth's surface to the free troposphere was heavily monitored during the entire day, with particular focus on the time period between noon and sunset.

The main purpose of the BLLAST campaign was the investigation of the turbulence decay during the afternoon transition, in particular the characterization of the transition from a fully developed and highly turbulent convective boundary layer (CBL) towards evening conditions (characterized by the transformation of the CBL into the less turbulent residual layer) and the growth of a stable boundary layer (SBL) from the ground. A particular focus of the campaign was directed at the effects of heterogeneity on this transition, including both the local scale (e.g. small-scale variability of surface and vegetation properties) and the mesoscale (e.g. the topography of the Lannemezan site in the proximity of the Pyrenees), leading to persistent thermally driven flow patterns in the area under certain synoptic conditions.

\subsection{RPAS operations}

The BLLAST campaign was, to the knowledge of the authors, the first ABL campaign to use coordinated operations between manned and small remotely piloted aircraft systems as an integrated measurement strategy for the probing of the ABL and relevant properties of the underlying surface. The main intention was to close the observational gap between the fixed- and local-scale measurements by groundbased in situ and remote sensing instrumentation as well as the fast moving sensors used for observations of the regional scale on the two participating manned aircraft, a Piper Aztec from SAFIRE in France (Saïd et al., 2005) and a Sky Arrow from CNR in Italy (Gioli et al., 2006). It turned out that RPA systems, in particular SUMO with its small size, low weight and a resulting hand-start capability, provided a flexible and

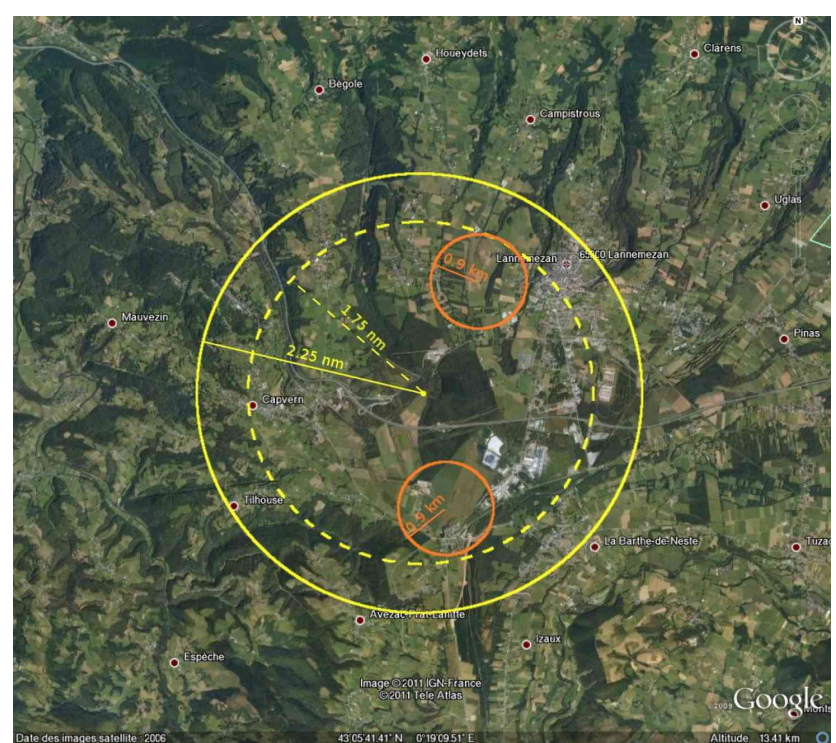

Figure 1. The temporary restricted area activated for the RPAS operations during the BLLAST campaign. The solid yellow line indicates the outer boundary of the 2.25 nautical mile $(\mathrm{nm})$ zone reserved and the dashed one the $1.75 \mathrm{~nm}$, finally available for the RPAS operations due to an additional required safety buffer towards general airspace. The two small circles indicate the zones around the Sites 1 and 2, where all RPAS operations took place.

fast solution for atmospheric profiling that, amongst others, was highly beneficial for the mission planning of the manned aircraft operations.

The key to the successful operation of different RPAS during the BLLAST campaign was a collaborative effort between the French Civil Aviation Authority (DGAC), the operators of the Lannemezan observatory and the individual groups flying RPAS, upfront and during the campaign. In a first step, a temporary restricted airspace (TRA) was established. The area was a cylinder with a radius of 2.25 nautical miles $(\mathrm{nm})$ centred at $43^{\circ} 6^{\prime} 18^{\prime \prime} \mathrm{N}$ and $0^{\circ} 21^{\prime} 6^{\prime \prime} \mathrm{E}$ (see Fig. 1) that covers both heavily instrumented Sites 1 and 2 of the campaign (small orange circles in the figure). The solid yellow line indicates the outer boundary of the $2.25 \mathrm{~nm}$ zone, the dashed one indicates the $1.75 \mathrm{~nm}$ zone, finally available for the RPAS operations due to an additional required horizontal safety buffer towards general airspace. The overall vertical extension of the TRA was $7500 \mathrm{ft}$. Considering a mandatory $500 \mathrm{ft}$ safety buffer on top and the surface elevation of ca. $600 \mathrm{~m}$ in the area, the vertical range of RPAS operations was constrained to an altitude of approx. $1500 \mathrm{~m}$ above ground. During the campaign the TRA was generally activated for $16 \mathrm{~h}$ per day from 05:00 to 21:00 UTC. In a second step each RPAS group had to apply individually to DGAC for an aircraft-specific flight permission. In general, both coordinated multiple RPAS missions and beyond line of sight (BLOS) operations had been approved during the campaign, i.e. allowing SUMO to frequently probe the whole available 
vertical range of the TRA. During multiple RPAS missions at Site 1, an appointed RPAS coordinator was responsible for the coordination of the different groups and the internal segregation of the RPAS airspace to avoid danger of collisions.

During parallel operations with the manned research aircraft, the RPAS coordinator was also in direct radio contact with the pilots. Particular limitations for RPAS operations during the activation hours of the TRA applied to time periods with an active flight plan for the two manned research aircraft that had special permission to enter the TRA. Both the Sky Arrow and the Piper Aztec have a typical endurance of ca. $2 \mathrm{~h}$ for a scientific mission. Depending on whether the strategy of each individual IOP with manned aircraft participation uses one or both aircraft, and for the latter case either flying sequentially or in parallel, RPAS missions were altitude-limited for a period between 2 and $8 \mathrm{~h}$ during the afternoon of the corresponding day. In those situations, RPAS and manned aircraft had to keep a vertical separation of at least $500 \mathrm{ft}$. In practice, this meant that during IOPs with manned and RPAS operations, all RPAS had to stay at least $500 \mathrm{ft}$ below the lowest approved flight level for the manned aircraft mission.

Besides SUMO, two other RPA systems participated during the whole BLLAST campaign, the Meteorological Mini Aerial Vehicle ( $\left.\mathrm{M}^{2} \mathrm{AV}\right)$-Carolo from the University of Braunschweig (Martin et al., 2011) and the Multipurpose Airborne Sensor Carrier (MASC) from the University of Tübingen (Wildmann et al., 2014) (see Fig. 2). Both systems are particularly suited for flying kilometre-scale-level legs and performing high-frequency measurements of wind components, temperature and humidity fluctuations and therefore for the determination of heat, momentum and moisture fluxes (e.g. van den Kroonenberg et al., 2012; Wildmann et al., 2013). The MASC system, participating in a prototype version, suffered from technical problems and no data sets could be supplied to the BLLAST data archive (http://bllast.sedoo.fr/ database/). A number of other RPAS only participated during the last two weeks of the BLLAST campaign (for details see Lothon et al. (2014)). These adjunct operations were performed as a RPAS test and sensor intercomparison event, organized by the European COST Action ES0802 "Unmanned Aerial Systems in Atmospheric Research" (Lange and Reuder, 2013). The main scientific contributions of those RPAS operations were Octocopter flights performed by the University of Applied Sciences Ostwestfalen-Lippe for micro-scale air and surface-temperature surveys (Cuxart et al., 2016) and orthophoto flights with the RPAS Sirius (University of Heidelberg and Karlsruhe Institute of Technology) providing an areal camera survey of the Sites 1 and 2 with a resolution higher than $5 \mathrm{~cm}$.

\subsection{SUMO operations during the campaign}

Three identical SUMO airframes were operated during the BLLAST campaign. They successfully completed a total of

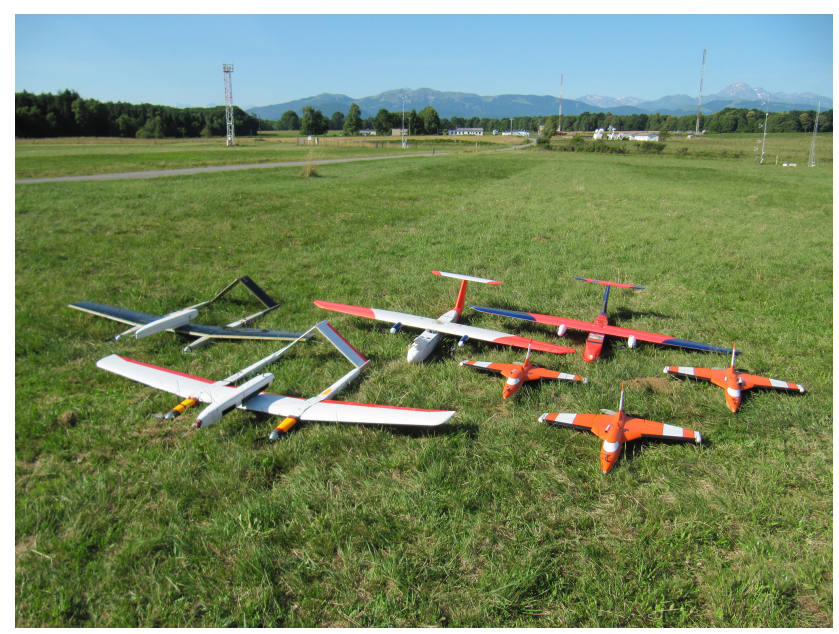

Figure 2. The fleet of RPAS operated during the whole BLLAST campaign at Site 1 in Lannemezan. From left to right: MASC (University of Tübingen), $\mathrm{M}^{2} \mathrm{AV}$ (University of Braunschweig) and SUMO (University of Bergen). In the background the Pyrenees and the Site $160 \mathrm{~m}$ instrumented tower in the upper right corner.

299 individual flight missions on 23 days over the period between 13 June and 8 July 2011 (see Table 2). The majority of the flights were performed during the 12 Intensive Operational Periods (IOPs) of the experiment (Lothon et al., 2014). Three different types of scientific missions were conducted, namely atmospheric profiles (168 flights), areal surveys (74 flights) and turbulence transects (49 flights) and are described in more detail in the following. The remaining eight flights were dedicated to system tests and autopilot tuning.

\subsubsection{Profiles}

The profile missions were performed as helical flight patterns along the wall of an imaginary cylinder with a diameter of $120 \mathrm{~m}$ (see Fig. 3). The maximum flight altitude was limited by the vertical extension of the TRA to $7000 \mathrm{ft}$, corresponding to approximately $1500 \mathrm{~m}$ above the ground level of slightly above $600 \mathrm{~m}$. Due to energy efficiency considerations, SUMO was operated with a rather high ascent speed of ca. $7-10 \mathrm{~m} \mathrm{~s}^{-1}$. During the descent, usually in gliding mode without using the engine, the vertical velocity is considerably lower in the order of $2-3 \mathrm{~m} \mathrm{~s}^{-1}$. The data acquisition rates for temperature and humidity of $2 \mathrm{~Hz}$ results in a vertical resolution for the corresponding profiles of approximately $5 \mathrm{~m}$ for the ascent and $1 \mathrm{~m}$ for the descent. The flight pattern provides two consecutive profiles of the atmospheric parameters within a time window of about $15 \mathrm{~min}$. The time constants of the temperature and humidity sensors in use, typically about several seconds, result in slightly shifted profiles during ascent and descent. Assuming stationary conditions, this can be numerically corrected (Jonassen, 2008). In addition, these data also provide information on the magnitude of the temperature sensor time constants. 
Table 2. SUMO operations during the BLLAST campaign.

\begin{tabular}{lcccccc}
\hline Date & IOP & Total & Test & Profile & Survey & Turbulence \\
\hline 13.06. & - & 7 & 3 & & & 4 \\
14.06. & 0 & 3 & & & 1 & 2 \\
15.06. & 1 & 22 & 1 & & 2 & 19 \\
16.06. & - & 1 & 1 & & & \\
17.06. & - & 11 & & 7 & 2 & 2 \\
18.06. & - & 5 & & 5 & & \\
19.06. & 2 & 28 & & 12 & 13 & 3 \\
20.06. & 3 & 23 & & 11 & 10 & 2 \\
21.06. & - & 8 & & 8 & & \\
23.06. & - & 2 & & 2 & & \\
24.06. & 4 & 12 & & 10 & 2 & \\
25.06. & 5 & 23 & 1 & 11 & 9 & 2 \\
26.06. & 6 & 25 & 2 & 11 & 8 & 4 \\
27.06. & 7 & 35 & & 12 & 12 & 11 \\
30.06. & 8 & 18 & & 12 & 6 & \\
01.07. & 9 & 11 & & 6 & 5 & \\
02.07. & 10 & 17 & & 14 & 3 & \\
03.07. & - & 6 & & 6 & & \\
04.07. & - & 9 & & 9 & & \\
05.07. & 11 & 14 & & 13 & 1 & \\
06.07. & - & 7 & & 7 & & \\
07.07. & - & 8 & & 8 & & \\
08.07. & - & 4 & & 4 & & \\
\hline Total & & 299 & 8 & 168 & 74 & \\
\hline & & & & & & \\
\hline
\end{tabular}

\subsubsection{Areal surveys}

The areal surveys consisted of consecutive parallel transects in east-west and north-south direction over a distance of $150 \mathrm{~m}$ (see Fig. 4). With the capacity of one battery pack (2600 mAh), approximately $1 \mathrm{~m}^{2}$ could be covered by one flight. The flights should be performed at rather low altitudes to minimize longwave absorption and emission from the atmospheric layer between the infrared (IR) sensor on SUMO, used to monitor the surface temperature, and the ground. For the BLLAST campaign, altitudes between 65 and $80 \mathrm{~m}$ were chosen to ensure sufficient vertical clearance from buildings, trees and the $60 \mathrm{~m}$ meteorological mast at Site 1. At an altitude of $60 \mathrm{~m}$, the angle of view of the infrared sensor of $90^{\circ}$ results in a circular sensor footprint at the ground of $60 \mathrm{~m}$ diameter (assuming zero pitch and zero roll), over which the temperature information is averaged. In the post-processing of the IR data, all data points in which the aircraft had a pitch and/or roll angle larger than $10^{\circ}$ have been filtered out from the data set. This was done to avoid far field temperature signal errors. All the IR data from Site 1 have been corrected for an emissivity of 0.95 and for Site 2, the emissivity was set to 0.97 , corresponding to the different surface conditions at the two sites.

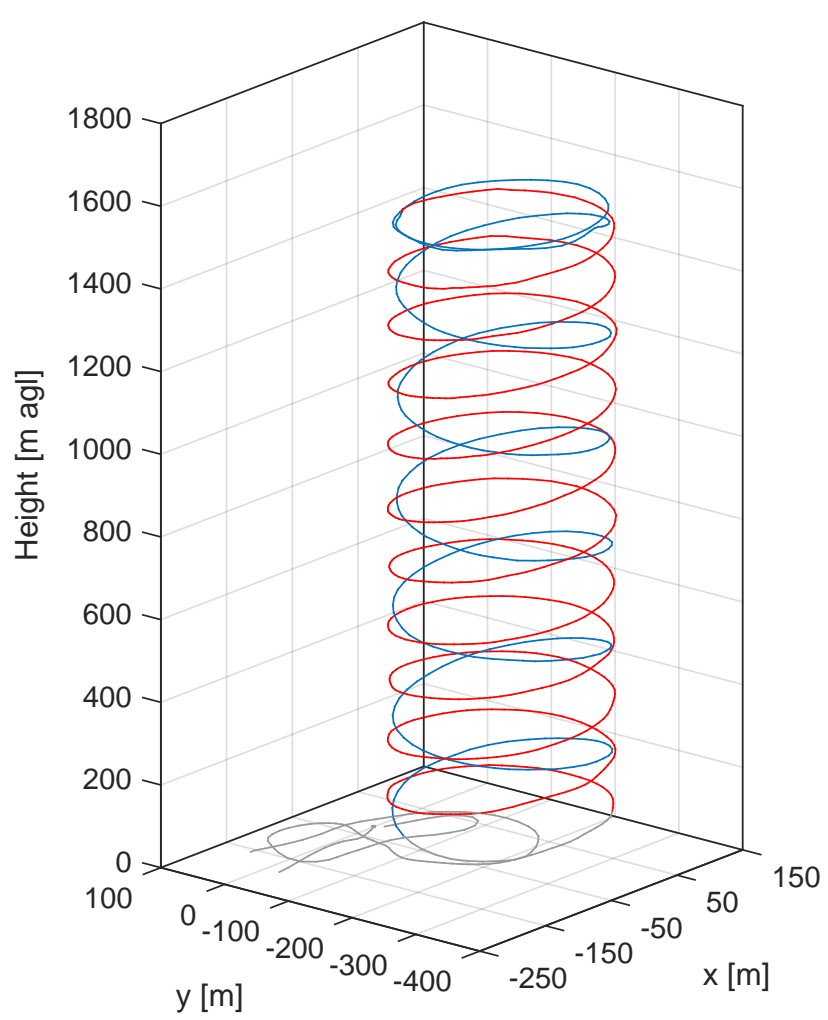

Figure 3. Typical atmospheric profiling flight pattern during the BLLAST campaign. The ascent is coloured in blue, the descent in red.

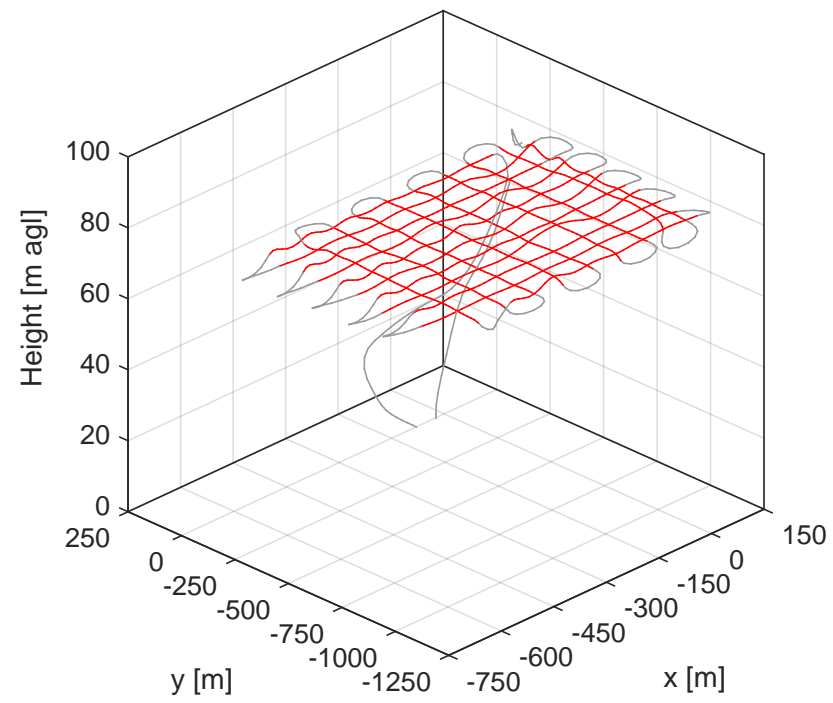

Figure 4. Typical flight pattern for the surface-temperature surveys during the BLLAST campaign. Data are only evaluated for the straight flight legs coloured in red, where the infrared sensor is assumed to look vertically down. 


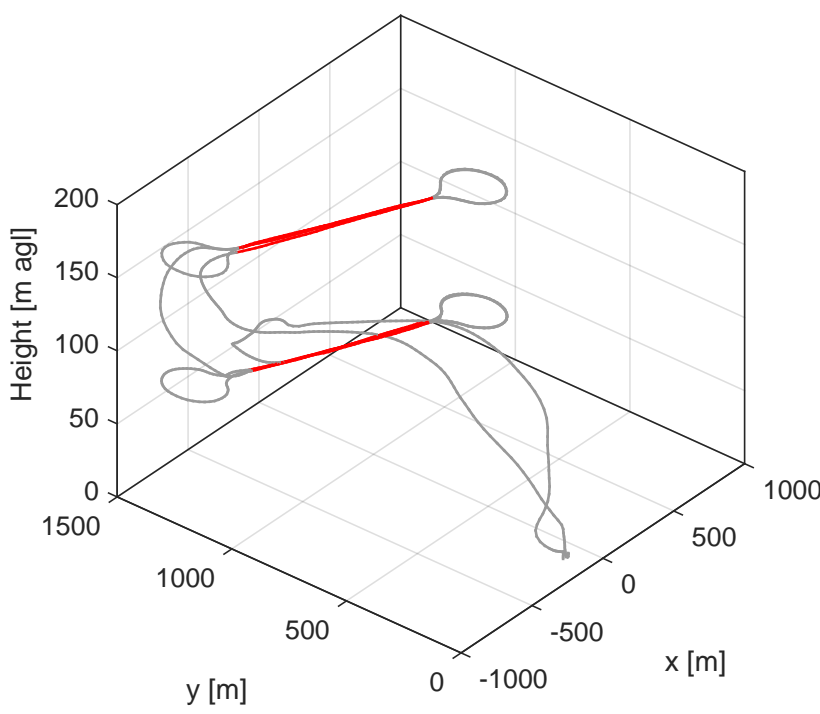

Figure 5. Typical flight pattern for the turbulence measurements during the BLLAST campaign. Turbulence data are only evaluated for the straight flight legs coloured in red.

\subsubsection{Turbulence transects}

The flight patterns for the turbulence transects consisted of straight legs of ca. $1 \mathrm{~km}$ length with turning circles on both ends (see Fig. 5). Only the straight leg, coloured in red, was used for the determination of the turbulence parameters. Depending on the ambient wind speed and direction, the typical flight time for a single $1 \mathrm{~km}$ leg was approximately 35 to $60 \mathrm{~s}$. Usually four straight legs, two in each direction, were performed at one altitude before climbing to the next level. Following this pattern, the battery capacity allowed for a maximum of four altitudes to be covered during one flight. These altitudes were chosen as 65, 130, 300 and $500 \mathrm{~m}$ above ground. Some flights covered only a subset of those altitudes and some flights were also covering a higher level of $1000 \mathrm{~m}$.

\section{Results}

This section gives an overview of the observational data set obtained by the different types of SUMO flight missions during the BLLAST campaign. Given the large number of flights, this is done using several typical examples. Nevertheless, we are confident that the presentation and discussion of those examples will provide a good picture of the information content of the SUMO data set that is already under investigation (e.g. Båserud et al., 2016; Cuxart et al., 2016; Lothon et al., 2014; Pietersen et al., 2015) and will be studied in even more detail in the future.

\subsection{Atmospheric profiling}

The vertical structure of the ABL was the target of more than half of the flight missions during the BLLAST campaign. During each IOP, SUMO typically provided more than 10 profiles over the day (see Table 2) and therefore contributed considerably to the monitoring of the diurnal development of the CBL in high temporal resolution. The short pre-flight preparation time of the SUMO system (about $10 \mathrm{~min}$ ) allowed for a fast and flexible measurement programme, providing in situ observations of the vertical structure of the atmosphere in near real time. The corresponding information from flights performed prior to the daily morning briefing was important for providing decision support for the further measurement programme of an IOP, e.g. for detailed planning of the flight levels of the manned aircraft missions or for the vertical distribution of sensors and the measurement strategy of the tethered balloon deployments.

Figures 6 and 7 present two examples of the diurnal development of the ABL for 19 June (IOP 2) and 21 June (a non-IOP day), 2 days with rather different BL structure and dynamics. The first flight at 06:00 UTC on June 19 shows a shallow stable layer at the ground and a well-mixed residual layer above, up to an altitude of $1200 \mathrm{~m}$. During the day, the whole BL was warming and moistening and the capping inversion was continuously descending, reaching a level of around $700 \mathrm{~m}$ at 21:00 UTC. This is a clear signature of synoptic-scale dynamic subsidence. The last profile again shows the development of a surface inversion and a slight stabilizing tendency in the residual layer above. The free atmosphere (FA) warmed approximately $5 \mathrm{~K}$ over the course of the day and the specific humidity $q$ increased from values of below $1 \mathrm{~g} \mathrm{~kg}^{-1}$ to more than $7 \mathrm{~g} \mathrm{~kg}^{-1}$, both also indicating a considerable influence of warm and moist air advection. The profiles taken around noon and in the early afternoon also exhibit a higher local variability, both in temperature and humidity, within the capping inversion, suggesting the presence of small-scale processes modifying the entrainment zone. A relatively shallow ABL characterizes 21 June and Fig. 7 presents its development for a $5 \mathrm{~h}$ period around noon. The first ascent of SUMO at 09:00 UTC shows a CBL of around $300 \mathrm{~m}$ depth capped by an extended stable layer up to $800 \mathrm{~m}$. From 09:23 to 14:00 UTC, the CBL warmed by $4 \mathrm{~K}$ and finally grew to around $600 \mathrm{~m}$, where it merged with the top of the very stable layer that simultaneously subsided. The FA above was slightly cooling, indicating weak cold air advection. The moisture increased from around 10 to $12 \mathrm{~g} \mathrm{~kg}^{-1}$ in the BL and from 7 to $8 \mathrm{~g} \mathrm{~kg}^{-1}$ in the FA.

The temporal resolution of the SUMO flights, typically about $1 \mathrm{~h}$, allows for a detailed analysis of the BL structure based on profiles fixed over one position, e.g. in contrast to the radio soundings performed that measure slant profiles along the balloon's trajectory. One example of such an advanced analysis is the estimation of turbulent flux profiles of sensible and latent heat from the profiles of the cor- 

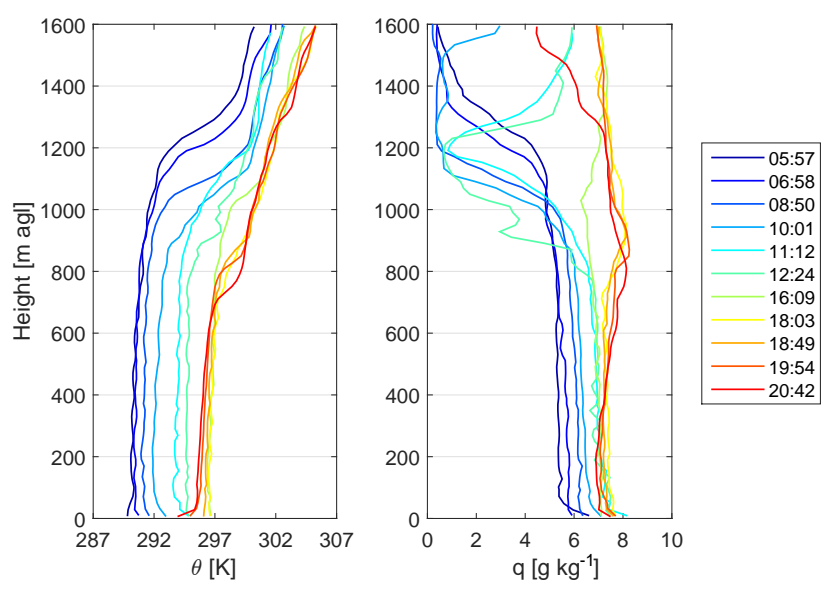

Figure 6. Profiles of potential temperature $\theta$ and specific humidity $q$ measured by SUMO on 19 June 2011 .
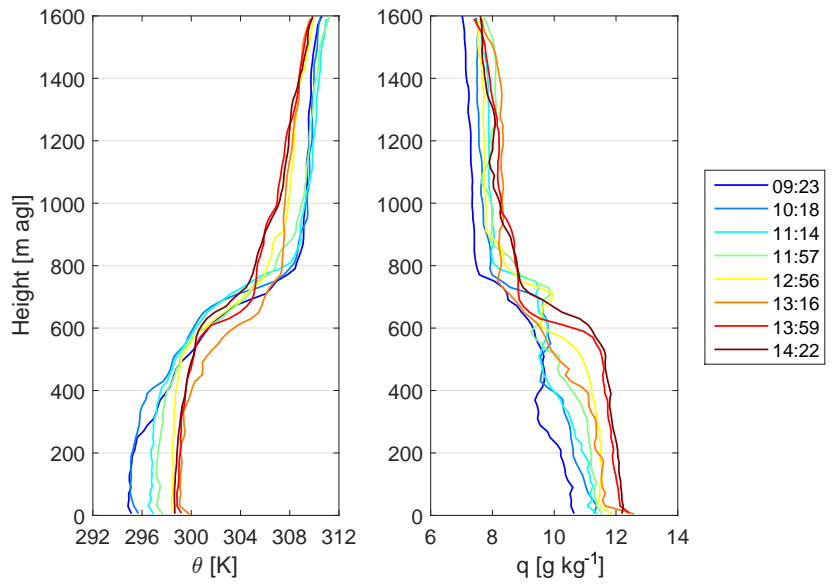

Figure 7. Profiles of potential temperature $\theta$ and specific humidity $q$ measured by SUMO on 21 June 2011.

responding mean quantities $\theta$ and $q$. The algorithm in use here has been developed and applied for observations by the RPAS SMARTSonde and is described in detail in Bonin et al. (2012), based on a method suggested by Deardorff et al. (1980). It is in general based on a simplified version of the prognostic equation for $\theta$ or $q$ and allows relating the change of the mean quantity with time to the corresponding flux divergence. Figure 8 presents two examples for calculated sensible heat flux profiles for 5 July. The profiles of $\theta$ (left panel) show a growth of the CBL from $400 \mathrm{~m}$ at 09:17 UTC to around $500 \mathrm{~m}$ at 10:29 UTC and finally ca. $800 \mathrm{~m}$ at 12:09 UTC. The sensible heat flux profiles (right panel) follow the expected shape in the CBL with a linear decrease in height and slightly negative values on top of the BL due to entrainment processes. The retrieved ground values of around $120 \mathrm{~W} \mathrm{~m}^{-2}$ fit very well with the observations from the network of the eddy-covariance stations for that time (Lothon et al., 2014). A thorough analysis of all
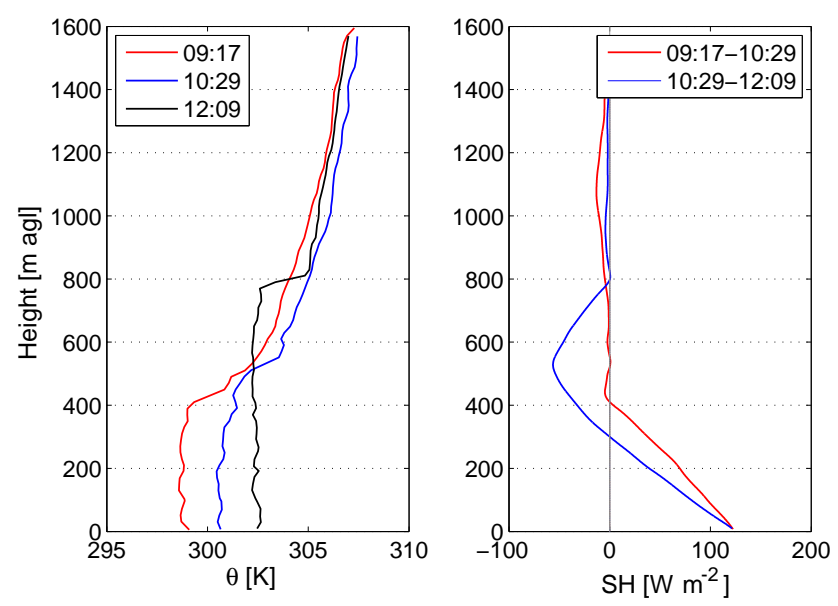

Figure 8. Three subsequent profiles of potential temperature $\theta$ taken on 5 July (left panel) and the corresponding calculated profiles of sensible heat flux (right panel).

available SUMO profiles under the aspect of flux profile determination is in progress and soon expected to result in a publication of its own.

\subsection{Areal surveys}

The areal surveys of the surface temperature were intended to provide supplementary information for the investigation of the heterogeneous surface forcing in selected regions of the campaign area, both for the CBL during the daytime and the SBL during the night. Such data are expected to aid in the interpretation of the point measurements by the surface energy balance stations, e.g. with respect to spatial representativeness. The BLLAST campaign offered the possibility of testing the potential of an airborne low-cost IR sensor for surface-temperature estimates against other well-established measurement methods, like pyrgeometers or 4-component net radiometers. In using the output of the radiometers, the upwelling longwave radiation has been converted into surface temperature using the following formula $T_{\mathrm{S}}=\sqrt[4]{\frac{\mathrm{LW}_{\text {out }}}{\epsilon \sigma}}$, where $T_{\mathrm{S}}$ is the surface temperature, $\mathrm{LW}_{\text {out }}$ is the upwelling longwave radiation, $\epsilon$ is the emissivity and $\sigma$ is the StefanBoltzmann constant $\left(5.67 \times 10^{-8} \mathrm{~W} \mathrm{~m}^{-2} \mathrm{~K}^{-4}\right)$. For Site 2, an $\epsilon$ of 0.97 was chosen, corresponding to the surface types there.

During the period from 14 June to 5 July, 24 areal surveys were performed at Site 1. Figures 9 and 10 show examples of surface temperatures measured by SUMO at Site 1 during the daytime and in the evening. Amongst the differences that stand out between the two cases is the fact that the small heterogeneity site (marked by a red box) is relatively warm during the daytime and relatively cold during the night. The soil in this rectangular area has in the past been compacted as foundation for a radar antenna array. As a consequence of the resulting structural changes, such as increased density 


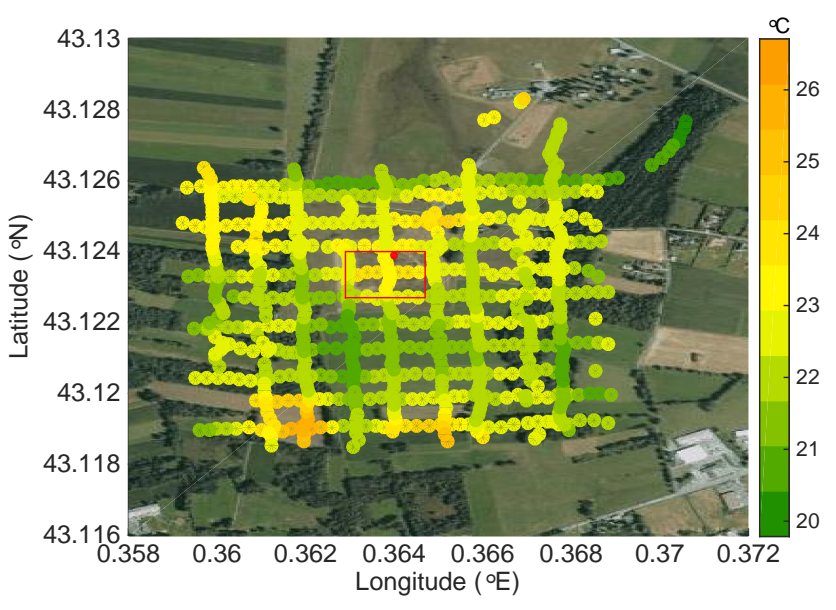

Figure 9. Surface temperature from Site 1 on 19 June 2011 at 19:41 UTC measured using the downward-looking SUMO IR sensor. Data are only shown for the straight flight legs, where the IR sensor is assumed to look vertically down. The red square marks the location of the "small-scale heterogeneity site".

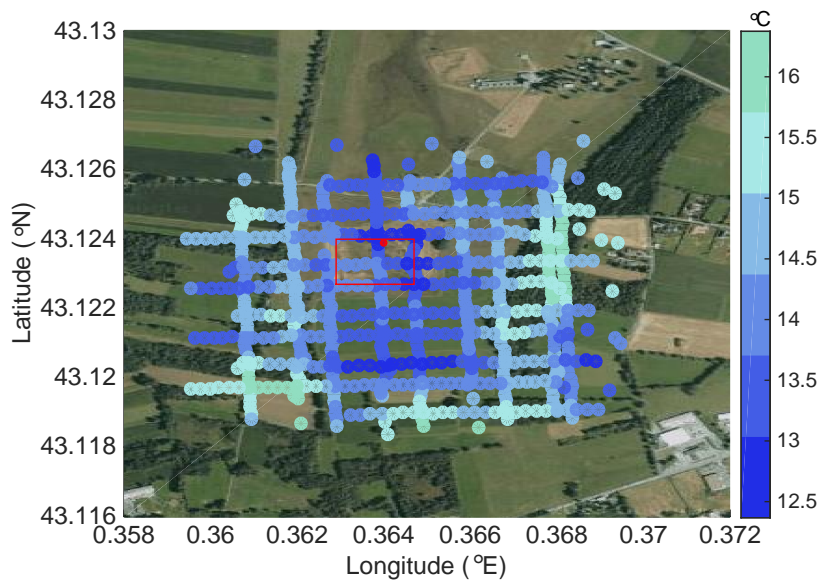

Figure 10. Same as in Fig. 9, but for 2 July 2011 at 17:43 UTC.

and lower soil moisture content, this area warms and cools distinctly faster than its surroundings. The observed differences, approximately a few $\mathrm{K}$, can be expected to have an impact on local circulations and thus the microclimate (e.g. Cuxart et al., 2016).

During the period from 25 to 27 June, a total of 28 areal surveys were performed at Site 2. Figure 11 shows an example of the surface-temperature field derived from SUMO measurements at Site 2 during the daytime. Four areas, expected to represent main characteristic surface types, are marked by coloured boxes: moor - characterized by a mixture of bare soil and sparse vegetation (blue), corn - a cultivated corn field with a canopy height of around $120 \mathrm{~cm}$ during the measurement (red), forest - a Douglas fir canopy with a typical tree height of 20-25 m (green) and waste site - an industrial area of waste disposal with a mixture of dry

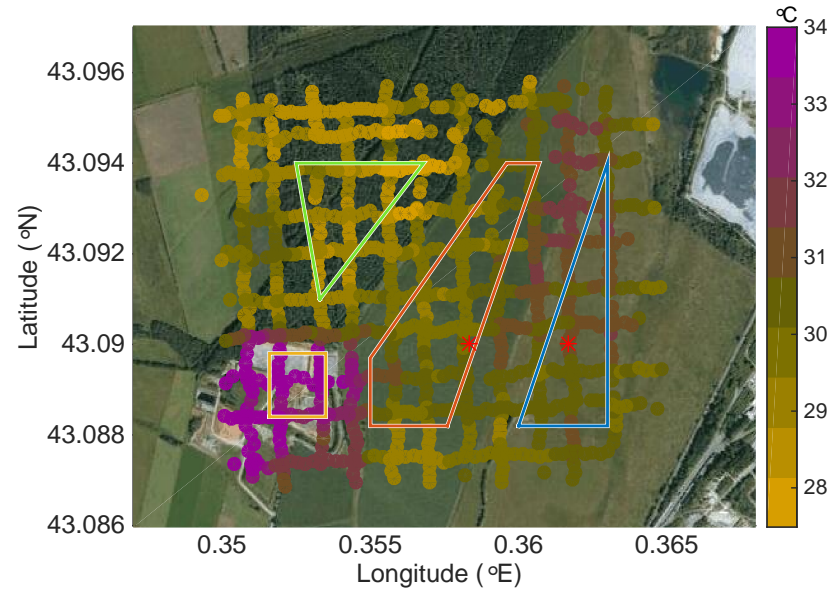

Figure 11. Surface temperature from Site 2 on 27 June 2011 at 13:15 UTC measured using the downward-looking SUMO IR sensor. Data are only shown for the straight flight legs, where the IR sensor is assumed to look vertically down. Four areas with characteristic surface types are marked with coloured boxes: moor (blue), corn (red), forest (green), waste site (orange). The locations of two net radiometers (AWS) within the moor and corn areas are marked as well.

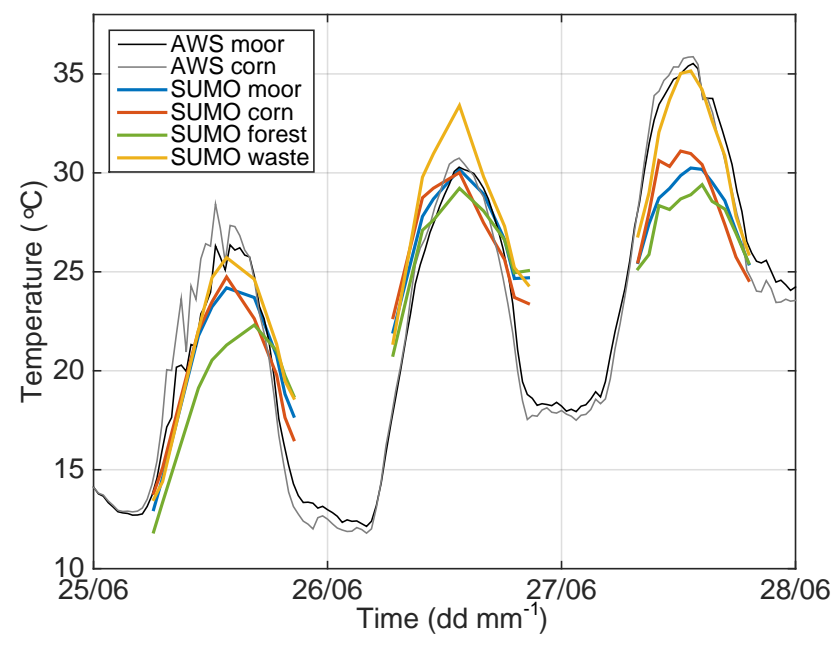

Figure 12. Time series of surface temperature from four different surface types at Site 2 measured using the downward-looking SUMO infrared sensor and two net radiometers.

gravel, asphalt and buildings (orange). The surface temperatures within the boxes for the four different characteristic areas have been averaged for each survey flight and the corresponding time series is presented in Fig. 12.

Amongst the four surface types, the forest clearly had the coldest infrared temperature signature at the beginning of the day until about noon. This can be recognized in both the horizontal survey data (Fig. 11) and in the time series (Fig. 12). This changed towards the night and in the latest measurements at about 20:30 UTC, when only the waste site 
was about as warm or warmer than the forest. The waste site had the highest maximum temperature in the SUMO data set, reaching almost $35^{\circ} \mathrm{C}$ on 27 June. The differences in surface temperature between the moor and corn fields are subtle, but clear. During night-time corn is cooler, while in the morning until about noon it is the warmer of the two. This goes with the fact that corn heats up the quickest in daytime and it also cools down the quickest at night. These findings are confirmed when considering the AWS surface-temperature observations from the corn and moor fields, which were obtained from Kipp \& Zonen CNR1 net radiometers.

When comparing the SUMO and AWS data, it is clear that at times they deviate considerably in both directions. At times, SUMO is clearly colder (e.g. midday of 25 and 27 June) but at others they show roughly the same temperature (26 June). On some occasions, the SUMO measurements are even slightly warmer, e.g. in the nights of 25 and 26 June. Several factors may contribute to such differences when comparing the ground-based radiometers and the airborne IR sensor on SUMO. One factor that has to be taken into account is that the AWS measurements only represent point measurements that are limited in space and are presumably strongly dominated by the local conditions. The RPAS data, on the other hand, are averaged over considerably larger areas and derived from footprints that are already averages over ca. $10000 \mathrm{~m}^{2}$. Another probably even more important factor is the distance between sensor and surface. The AWS measurements were made at heights of $2 \mathrm{~m}$ (moor) and $2.8 \mathrm{~m}$ (corn) above the ground, while the SUMO measurements were performed at an average elevation of around $75 \mathrm{~m}$ (Site 1) and $69 \mathrm{~m}$ (Site 2). It is well known, e.g. from the retrieval of sea surface temperatures using satellites, that parts of the infrared radiance from the surface is attenuated and potentially re-emitted by the atmosphere before it reaches the radiometer (e.g. Kilpatrick et al., 2001). Corrections for atmospheric effects are therefore done for IR satellite data on a routine basis. Amongst the atmospheric constituents, water vapour has been found to have the strongest effect in this regard. Different correction algorithms have been proposed to correct for atmospheric effects (e.g. Grassl and Koepke, 1981; Holyer, 1984). In this study, we have in a first step used a simple correction based on a multiple linear regression algorithm using the following predictor variables: the IR surface temperature measured by the AWS, specific humidity and air temperature measured by SUMO and the SUMO altitude. The regression was performed on six independent flights from 26 and 27 June in which straight legs (transects) were flown at two different elevations (around 60 and $150 \mathrm{~m}$ ) above the moor. The results of this simple correction method are presented in Fig. 13.

It can be seen that the agreement between the AWS and SUMO-based surface-temperature estimates has now clearly improved. Taking the AWS data as reference, the root mean square error in the SUMO data is reduced from 3.0 to $1.9^{\circ} \mathrm{C}$ when comparing the original data with those obtained by the

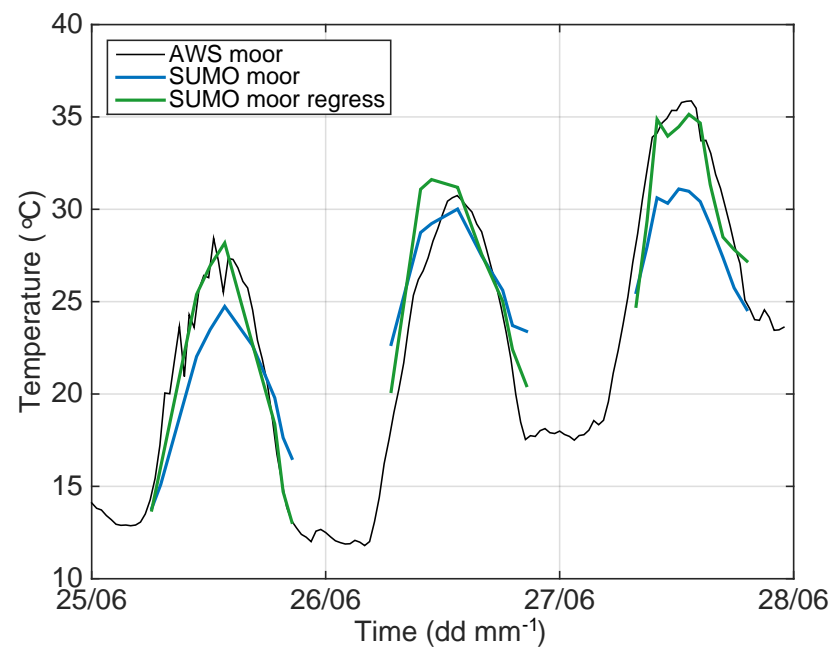

Figure 13. Time series of surface temperature from the moor area using a net radiometer, unaltered SUMO data and corrected SUMO data using the multiple linear regression algorithm.

linear regression algorithm. Although there is uncertainty remaining, this shows the general potential of the SUMO IR measurements for surface-temperature retrieval. Future studies are required to improve and fine-tune the simple algorithm described above or to apply a more advanced correction algorithm. The BLLAST data set provides several further opportunities for corresponding improvement and validation, e.g. by consideration of further data sets from a net-radiometer (Eppley-PIR, model 29435F3) operated by the Physical-meteorological Observatory Davos World Radiation Centre (PMOD/WRC) (Gröbner et al., 2009) on the small-scale heterogeneity field at Site 1 or from the thermal IR camera (FLIRA320) operated on the $60 \mathrm{~m}$ tower by the University of California, San Diego (Garai et al., 2013). This is, however, more than enough material for a separate publication and clearly outside the scope of this paper.

\subsection{Turbulence}

The BLLAST campaign was one of the first real world applications adapting the 5HP-based turbulence system to SUMO and should be considered a test and validation campaign for that purpose. Technical imperfections, such as the use of two different data loggers for the 5HP data and the aircraft attitude required for the motion compensation, as well as different sampling rates for both data sets, required elaborate processing of the data. Further details can be found in Båserud et al. (2016). Another issue that occurred during the campaign was an instability in the altitude control of the autopilot system, which was not handled correctly by the motion compensation algorithm, leading to artificial modulations in the vertical velocity component (see lower panel of Fig. 14) in the $100 \mathrm{~Hz}$ time series. The horizontal components $u$ and $v$ are completely unaffected by this feature. 

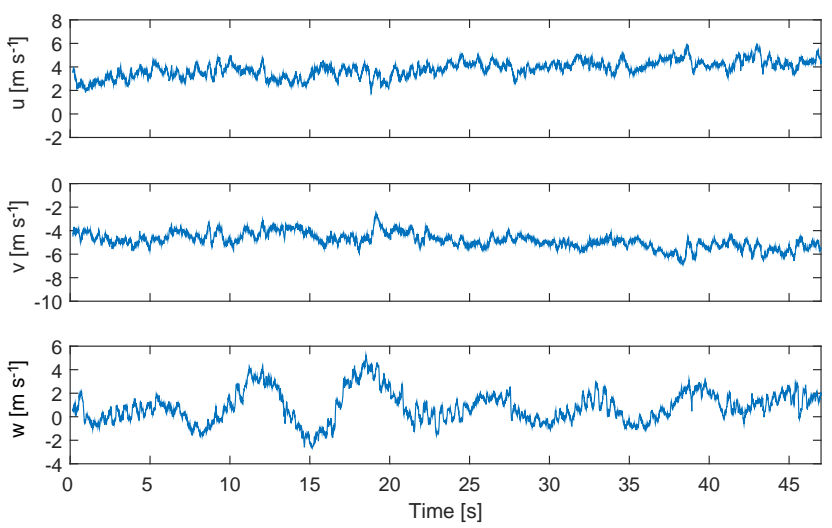

Figure 14. Example for the time series of the wind components $u, v$ and $w$ in the meteorological coordinate system derived from the SUMO 5HP system in a temporal resolution of $100 \mathrm{~Hz}$. The data for one single leg of flight \# 29 on 19 June 2011 between 15:50:37 and 15:51:23 UTC are presented.

During 19 and 20 June, four turbulence transect flight missions were performed in the vicinity of the $60 \mathrm{~m}$ tower that was equipped with a sonic anemometer (Campbell CSAT-3) on the top level for comparison purposes. The corresponding SUMO flight altitude was between 65 and $75 \mathrm{~m}$. The energy spectra for the velocity components $u, v$ and $w$ for flight \# 29 on June 19 around 16:00 UTC are presented in Fig. 15. They show a good agreement for the horizontal components in the energy level between the SUMO and the sonic data sets, except for a region of enhanced energy in the SUMO spectra at around $1 \mathrm{~Hz}$. This is most likely related to a frequency of the internal attitude control of the autopilot system that creates additional motions that are misinterpreted as real atmospheric motions. This feature must and will be further investigated in the future. For the vertical component, the SUMO data again follow the expected $-5 / 3$ slope of the inertial subrange over a wide range of frequencies, but generally show a too high overall energy level. The peak around $0.1 \mathrm{~Hz}$ is clearly related to the modulations in the vertical velocity shown in the lower panel of Fig. 14) and is described earlier. The reason for the overall shift towards higher energy content is not yet clear and also requires further investigation.

Figure 16 presents the energy spectra for flight \# 31 on 20 June around 16:00 UTC. It shows the same general behaviour for the SUMO system, but reveals an interesting feature for the sonic anemometer at the $60 \mathrm{~m}$ tower. With a wind direction from the north-east, the sonic anemometer is clearly located partly in the mast shadow, leading to an enhanced energy content in all three velocity components for this instrument.

\section{Summary and outlook}

Operations of RPAS were a substantial part of the ABL measurement strategy during the BLLAST campaign in June and July 2011. Several fixed-wing and rotary-wing systems contributed with measurements of atmospheric parameters and relevant surface properties. With multiple RPAS operations and the coordinated operations of manned and unmanned research aircraft BLLAST was without doubt a milestone in the application of such systems for atmospheric research.

The experience with the application procedure for the required flight permissions was in general very positive. Good communication, mutual understanding between the aviation authorities and the RPAS research groups and a bit of pragmatism were the keys to success in this context. The available airspace for RPAS operations in the TRA up to about $1500 \mathrm{~m}$ above ground was in most cases sufficient to probe the relevant parts of the ABL and the lower FA to achieve the scientific goals of the campaign.

The RPA system SUMO performed a total number of 299 scientific flights during the BLLAST campaign. Three different types of missions were performed: vertical profiling of the mean meteorological parameters temperature, humidity and wind, horizontal surveys of the surface temperature and horizontal transects for the estimation of turbulence parameters. The main purpose of the SUMO flight strategy was atmospheric profiling in high temporal resolution. A total of 168 profile flights were performed during the campaign with typically more than 10 flights per IOP day. The collected data allow for a detailed study of boundary-layer structure and dynamics and will in the future also be used for further analysis, e.g. the determination of profiles of sensible and latent heat fluxes. The first tests of a corresponding method have shown very promising results and have provided surfaceflux values in close agreement with those from ground-based eddy-covariance measurements. A follow-on study and publication, dedicated specifically to this scientific question, is in preparation. In addition, 74 horizontal surveys of the IR emission of the surface were performed at altitudes of around $65 \mathrm{~m}$. Each of those surveys typically covers an area of around $1 \mathrm{~km}^{2}$ and allows for an estimation of the surfacetemperature variability, an important piece of information for the assessment of the heterogeneity of the surface forcing as a function of soil and vegetation properties. The comparison with other surface-temperature measurements shows that the raw data of the airborne and ground observations can differ considerably, but that even a very simple multiple regression method can reduce those differences to a large degree. A more detailed analysis of the acquired surface-temperature data, including improved correction algorithms for atmospheric absorption and re-emission and a comparison and validation by consideration of further data sets, e.g. from a net-radiometer (Eppley-PIR, model 29435F3) and thermal IR camera (FLIRA320), is also planned. Forty-nine flight missions for the measurement of velocity variance were re- 

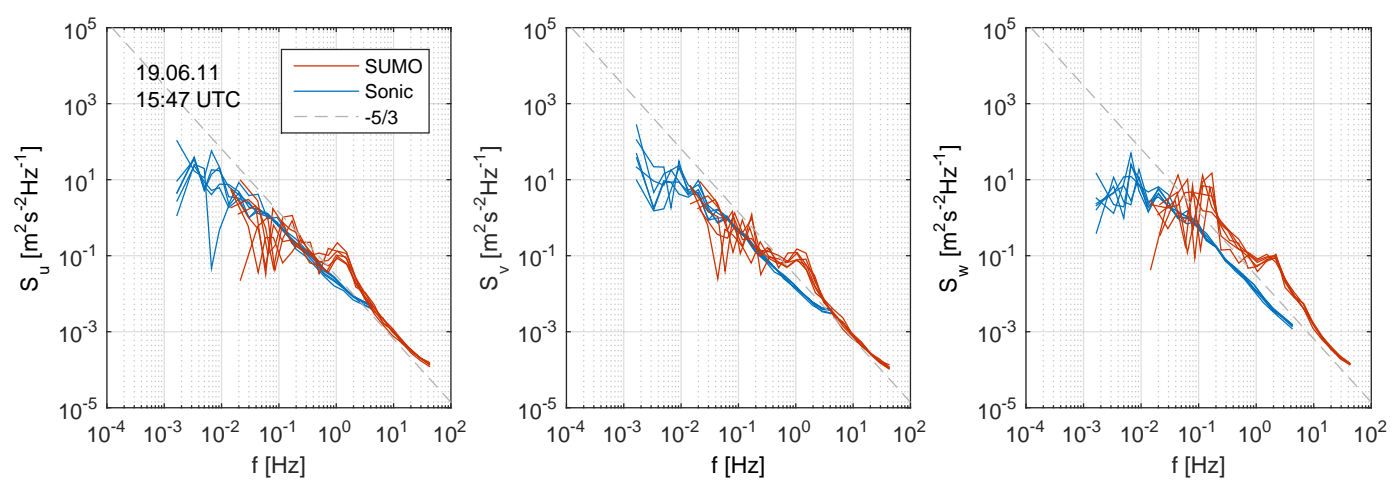

Figure 15. Energy spectra of the velocity variances of the $u, v$ and $w$ component from SUMO (red) and the sonic anemometer at the $60 \mathrm{~m}$

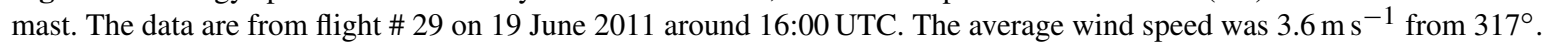
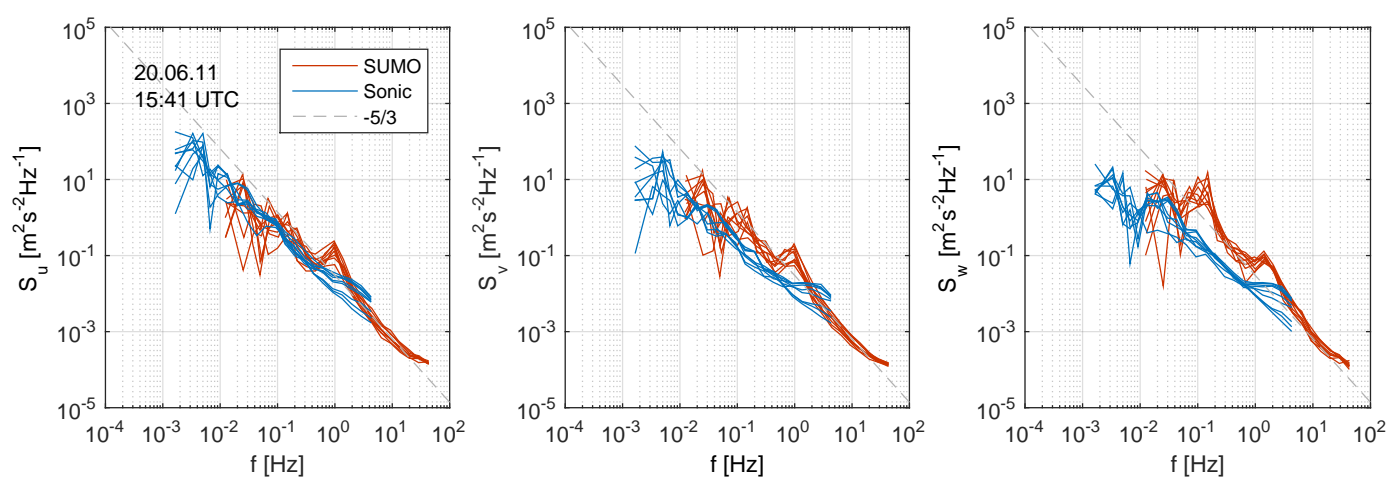

Figure 16. Energy spectra of the velocity variances of the $u, v$ and $w$ component from SUMO (red) and the sonic anemometer at the $60 \mathrm{~m}$ mast. The data are from flight \# 31 on 20 June 2011 around 16:00 UTC. The average wind speed was $2.7 \mathrm{~m} \mathrm{~s}^{-1}$ from $53^{\circ}$.

alized during the BLLAST campaign. For that, SUMO has been equipped with a 5HP sensor for the determination of the flow vector at $100 \mathrm{~Hz}$. In particular, for this application there is still need for further improvement with respect to the aircraft and sensor hard- and software, as well as the algorithms and methods for data analysis and interpretation. The main technical challenges to be addressed in this context are the logging of the aircraft attitude from the IMU sensors with $100 \mathrm{~Hz}$ and a reliable method for the determination of the yaw angle of the aircraft during flight, which is required for an accurate motion correction.

Acknowledgements. The BLLAST field experiment was made possible thanks to the contribution of several institutions and supports: INSU-CNRS (Institut National des Sciences de l'Univers, Centre national de la Recherche Scientifique, LEFE-IDAO programme), Météo-France, Observatoire Midi-Pyrénées (University of Toulouse), EUFAR (EUropean Facility for Airborne Research) and COST ES0802 (European Cooperation in Science and Technology). The field experiment would not have occurred without the contribution of all participating European and American research groups, which have all contributed a significant amount. The BLLAST field experiment was hosted by the instrumented site of Centre de Recherches Atmosphériques, Lannemezan, France
(Observatoire Midi-Pyrénées, Laboratoire d'Aérologie). BLLAST data are managed by SEDOO, from Observatoire Midi-Pyrénées. The participation of the Meteorology Group of the Geophysical Institute, University of Bergen was facilitated by contributions of the Geophysical Institute and the Faculty of Mathematics and Natural Sciences under the "små driftsmidler" scheme, a travel stipend by the Meltzer Foundation in Bergen and the Short Term Scientific Mission (STSM) scheme within the COST Action ES0802 "Unmanned Aerial Vehicles in Atmospheric Research". The authors are grateful to Anak Bhandari for the technical assistance in the preparation of the campaign and to Christian Lindenberg, the SUMO chief pilot during BLLAST. Without his passion, determination and patience we would never have achieved such a large number of flights.

Edited by: E. Pardyjak

\section{References}

Aeroprobe: On-The-Fly! Air Data System User's Manual Revision F, 1/2012, 2012.

Bå serud, L., Flügge, M., Bhandari, A., and Reuder, J.: Characterization of the SUMO Turbulence Measurement System for 
Wind Turbine Wake Assessment, Energy Procedia, 53, 173-183, doi:10.1016/j.egypro.2014.07.226, 2014.

Båserud, L., Reuder, J., Jonassen, M. O., Kral, S. T., Paskyabi, M. B., and Lothon, M.: Proof of concept for turbulence measurements with the RPAS SUMO during the BLLAST campaign, Atmos. Meas. Tech. Discuss., doi:10.5194/amt-2015-407, in review, 2016.

Bonin, T., Chilson, P., Zielke, B., and Fedorovich, E.: Observations of the Early Evening Boundary-Layer Transition Using a Small Unmanned Aerial System, Bound.-Lay. Meteorol., 146, 119-132, doi:10.1007/s10546-012-9760-3, 2012.

Brisset, P., Drouin, A., Gorraz, M., Huard, P.-S., and Tyler, J.: The Paparazzi solution, available at: http: //web.archive.org/web/20130624130619/http://paparazzi. enac.fr/papers_2006/mav06_paparazzi.pdf (last access: 13 June 2016), 2006.

Cassano, J. J.: Observations of atmospheric boundary layer temperature profiles with a small unmanned aerial vehicle, Antarct. Sci., 26, 205-213, 2014.

Cuxart, J., Wrenger, B., Martínez-Villagrasa, D., Reuder, J., Jonassen, M. O., Jiménez, M. A., Lothon, M., Lohou, F., Hartogensis, O., Dünnermann, J., Conangla, L., and Garai, A.: Estimation of the advection effects induced by surface heterogeneities in the surface energy budget, Atmos. Chem. Phys. Discuss., doi:10.5194/acp-2015-1051, in review, 2016.

Deardorff, J. W., Willis, G. E., and Stockton, B. H.: Laboratory studies of the entrainment zone of a convectively mixed layer, J. Fluid Mech., 100, 41-64, doi:10.1017/S0022112080001000, 1980.

Egger, J., Bajrachaya, S., Heinrich, R., Kolb, P., Lämmlein, S., Mech, M., Reuder, J., Schäper, W., Shakya, P., Schween, J., and Wendt, H.: Diurnal Winds in the Himalayan Kali Gandaki Valley. Part III: Remotely Piloted Aircraft Soundings, Mon. Weather Rev., 130, 2042-2058, doi:10.1175/15200493(2002)130<2042:DWITHK>2.0.CO;2, 2002.

Egger, J., Blacutt, L., Ghezzi, F., Heinrich, R., Kolb, P., Lämmlein, S., Leeb, M., Mayer, S., Palenque, E., Reuder, J., Schäper, W., Schween, J., Torrez, R., and Zaratti, F.: Diurnal Circulation of the Bolivian Altiplano. Part I: Observations, Mon. Weather Rev., 133, 911-924, doi:10.1175/MWR2894.1, 2005.

Elston, J., Argrow, B., Stachura, M., Weibel, D., Lawrence, D., and Pope, D.: Overview of Small Fixed-Wing Unmanned Aircraft for Meteorological Sampling, J. Atmos. Ocean. Tech., 32, 97-115, doi:10.1175/JTECH-D-13-00236.1, 2015.

Elston, J. S., Roadman, J., Stachura, M., Argrow, B., Houston, A., and Frew, E.: The tempest unmanned aircraft system for in situ observations of tornadic supercells: Design and VORTEX2 flight results, J. Field Robot., 28, 461-483, doi:10.1002/rob.20394, 2011

ENAC: Paparazzi user's manual, available at: http://wiki. paparazziuav.org/w/images/0/0a/Users_manual.pdf (last access: 13 June 2016), 2008.

Garai, A., Pardyjak, E., Steeneveld, G.-J., and Kleissl, J.: Surface Temperature and Surface-Layer Turbulence in a Convective Boundary Layer, Bound.-Lay. Meteorol., 148, 51-72, doi:10.1007/s10546-013-9803-4, 2013.

Gioli, B., Miglietta, F., Vaccari, F. P., Zaldei, A., and De Martino, B.: The Sky Arrow ERA, an innovative airborne platform to monitor mass, momentum and energy exchange of ecosystems, Ann. Geophys.-Italy, 49, 109-116, 2006.
Grassl, H. and Koepke, P.: Corrections for Atmospheric Attenuation and Surface Reflectivity in Satellite-Borne SST Measurements, in: Oceanography from Space SE - 13, edited by: Gower, J. F. R., vol. 13 of Marine Science, 97-107, Springer US, doi:10.1007/978-1-4613-3315-9_13, 1981.

Gröbner, J., Wacker, S., Vuilleumier, L., and Kämpfer, N.: Effective atmospheric boundary layer temperature from longwave radiation measurements, J. Geophys. Res., 114, D19116, doi:10.1029/2009JD012274, 2009.

Holland, G. J., Webster, P. J., Curry, J. A., Tyrell, G., Gauntlett, D., Brett, G., Becker, J., Hoag, R., and Vaglienti, W.: The Aerosonde Robotic Aircraft: A New Paradigm for Environmental Observations, B. Am. Meteorol. Soc., 82, 889-901, doi:10.1175/15200477(2001)082<0889:TARAAN>2.3.CO;2, 2001.

Holyer, R.: A two-satellite method for measurement of sea surface temperature, Int. J. Remote Sens., 5, 115-131, doi:10.1080/01431168408948793, 1984.

Jonassen, M. O.: The Small Unmanned Meteorological Observer (SUMO) - Characterization and test of a new measurement system for atmospheric boundary layer research, Master thesis, Geophysical Institiute, University of Bergen, Norway, 2008.

Jonassen, M. O., Ólafsson, H., Ágústsson, H., Rögnvaldsson, O., and Reuder, J.: Improving High-Resolution Numerical Weather Simulations by Assimilating Data from an Unmanned Aerial System, Mon. Weather Rev., 140, 3734-3756, doi:10.1175/MWR-D-11-00344.1, 2012.

Jonassen, M. O., Tisler, P., Altstädter, B., Scholtz, A., Vihma, T., Lampert, A., König-Langlo, G., and Lüpkes, C.: Application of remotely piloted aircraft systems in observing the atmospheric boundary layer over Antarctic sea ice in winter, Polar Res., 34, 25651, doi:10.3402/polar.v34.25651, 2015.

Kilpatrick, K. A., Podestá, G. P., and Evans, R.: Overview of the NOAA/NASA advanced very high resolution radiometer Pathfinder algorithm for sea surface temperature and associated matchup database, J. Geophys. Res., 106, 9179, doi:10.1029/1999JC000065, 2001.

Kocer, G., Mansour, M., Chokani, N., Abhari, R., and Müller, M.: Full-Scale Wind Turbine Near-Wake Measurements Using an Instrumented Uninhabited Aerial Vehicle, J. Sol. Energy., 133, 041011, doi:10.1115/1.4004707, 2011.

Konrad, T. G., Hill, M. L., Rowland, J. R., and Meyer, J. H.: A small, radio-controlled aircraft as a platform for meteorological sensor, APL Technical Digest, 10, 11-19, 1970.

Lange, M. and Reuder, J.: UAS Report COST Action ES0802 Unmanned Aerial Systems in Atmospheric Research, Tech. rep., ESF COST, available at: http://www.uib.no/filearchive/uas_ report_final.pdf (last acces: 13 June 2016), 2013.

Lothon, M., Lohou, F., Pino, D., Couvreux, F., Pardyjak, E. R., Reuder, J., Vilá-Guerau de Arellano, J., Durand, P., Hartogensis, O., Legain, D., Augustin, P., Gioli, B., Lenschow, D. H., Faloona, I., Yagüe, C., Alexander, D. C., Angevine, W. M., Bargain, E., Barrié, J., Bazile, E., Bezombes, Y., Blay-Carreras, E., van de Boer, A., Boichard, J. L., Bourdon, A., Butet, A., Campistron, B., de Coster, O., Cuxart, J., Dabas, A., Darbieu, C., Deboudt, K., Delbarre, H., Derrien, S., Flament, P., Fourmentin, M., Garai, A., Gibert, F., Graf, A., Groebner, J., Guichard, F., Jiménez, M. A., Jonassen, M., van den Kroonenberg, A., Magliulo, V., Martin, S., Martinez, D., Mastrorillo, L., Moene, A. F., Molinos, F., Moulin, E., Pietersen, H. P., Piguet, B., Pique, E., Román- 
Cascón, C., Rufin-Soler, C., Saïd, F., Sastre-Marugán, M., Seity, Y., Steeneveld, G. J., Toscano, P., Traullé, O., Tzanos, D., Wacker, S., Wildmann, N., and Zaldei, A.: The BLLAST field experiment: Boundary-Layer Late Afternoon and Sunset Turbulence, Atmos. Chem. Phys., 14, 10931-10960, doi:10.5194/acp14-10931-2014, 2014.

Martin, S., Bange, J., and Beyrich, F.: Meteorological profiling of the lower troposphere using the research UAV " $\mathrm{M}^{2} \mathrm{AV}$ Carolo", Atmos. Meas. Tech., 4, 705-716, doi:10.5194/amt-4-705-2011, 2011.

Mayer, S., Sandvik, A., Jonassen, M. O., and Reuder, J.: Atmospheric profiling with the UAS SUMO: a new perspective for the evaluation of fine-scale atmospheric models, Meteorol. Atmos. Phys., 116, 15-26, doi:10.1007/s00703-010-0063-2, 2010.

Mayer, S., Jonassen, M. O., Sandvik, A., and Reuder, J.: Profiling the Arctic Stable Boundary Layer in Advent Valley, Svalbard: Measurements and Simulations, Bound.-Lay. Meteorol., 143, 507-526, doi:10.1007/s10546-012-9709-6, 2012.

Pietersen, H. P., Vilà-Guerau de Arellano, J., Augustin, P., van de Boer, A., de Coster, O., Delbarre, H., Durand, P., Fourmentin, M., Gioli, B., Hartogensis, O., Lohou, F., Lothon, M., Ouwersloot, H. G., Pino, D., and Reuder, J.: Study of a prototypical convective boundary layer observed during BLLAST: contributions by large-scale forcings, Atmos. Chem. Phys., 15, 42414257, doi:10.5194/acp-15-4241-2015, 2015.

Reuder, J., Brisset, P., Jonassen, M., Müller, M., and Mayer, S.: The Small Unmanned Meteorological Observer SUMO: A new tool for atmospheric boundary layer research, Meteorol. Z., 18, 141147, doi:10.1127/0941-2948/2009/0363, 2009.

Reuder, J., Ablinger, M., Ágústsson, H., Brisset, P., Brynjólfsson, S., Garhammer, M., Jóhannesson, T., Jonassen, M. O., Kühnel, R., Lämmlein, S., Lange, T., Lindenberg, C., Malardel, S., Mayer, S., Müller, M., Ólafsson, H., Rögnvaldsson, O., Schäper, W., Spengler, T., Zängl, G., and Egger, J.: FLOHOF 2007: an overview of the mesoscale meteorological field campaign at Hofsjökull, Central Iceland, Meteorol. Atmos. Phys., 116, 1-13, doi:10.1007/s00703-010-0118-4, 2011.

Reuder, J., Jonassen, M. O., and Ólafsson, H.: The Small Unmanned Meteorological Observer SUMO: Recent developments and applications of a micro-UAS for atmospheric boundary layer research, Acta Geophys., 60, 1454-1473, doi:10.2478/s11600012-0042-8, 2012.
Saïd, F., Corsmeier, U., Kalthoff, N., Kottmeier, C., Lothon, M., Wieser, a., Hofherr, T., and Perros, P.: ESCOMPTE experiment: intercomparison of four aircraft dynamical, thermodynamical, radiation and chemical measurements, Atmos. Res., 74, 217 252, doi:10.1016/j.atmosres.2004.06.012, 2005.

Shuqing, M., Hongbin, C., Gai, W., Yi, P., and Qiang, L.: A miniature robotic plane meteorological sounding system, Adv. Atmos. Sci., 21, 890-896, doi:10.1007/BF02915591, 2004.

Spengler, T., Schween, J. H., Ablinger, M., Zängl, G., and Egger, J.: Thermally Driven Flows at an Asymmetric Valley Exit: Observations and Model Studies at the Lech Valley Exit, Mon. Weather Rev., 137, 3437-3455, doi:10.1175/2009MWR2779.1, 2009.

Spiess, T., Bange, J., Buschmann, M., and Vörsmann, P.: First application of the meteorological Mini-UAV "M2AV", Meteorol. Z., 16, 159-169, doi:10.1127/0941-2948/2007/0195, 2007.

Stenmark, A., Hole, L. R., Voss, P., Reuder, J., and Jonassen, M. O.: The influence of Nunataks on atmospheric boundary layer convection during summer in Dronning Maud Land, Antarctica, J. Geophys. Res.-Atmos., 119, 6537-6548, doi:10.1002/2013JD021287, 2014.

Subramanian, B., Chokani, N., and Abhari, R. S.: Drone-Based Experimental Investigation of Three-Dimensional Flow Structure of a Multi-Megawatt Wind Turbine in Complex Terrain, J. Sol. Energ., 137, 051007, doi:10.1115/1.4031038, 2015.

van den Kroonenberg, A. C., Martin, S., Beyrich, F., and Bange, J.: Spatially-Averaged Temperature Structure Parameter Over a Heterogeneous Surface Measured by an Unmanned Aerial Vehicle, Bound.-Lay. Meteorol., 142, 55-77, doi:10.1007/s10546011-9662-9, 2012.

Wildmann, N., Mauz, M., and Bange, J.: Two fast temperature sensors for probing of the atmospheric boundary layer using small remotely piloted aircraft (RPA), Atmos. Meas. Tech., 6, 21012113, doi:10.5194/amt-6-2101-2013, 2013.

Wildmann, N., Hofsäß, M., Weimer, F., Joos, A., and Bange, J.: MASC - a small Remotely Piloted Aircraft (RPA) for wind energy research, Adv. Sci. Res., 11, 55-61, doi:10.5194/asr-11-552014, 2014. 